\title{
E1 EMPLEO DE IMÁGENES LANDSAT TM PARA LA DETECCIÓN Y CARTOGRAFÍA DE ÁREAS INCENDIADAS EN EL PREPIRINEO OCCIDENTAL OSCENSE
}

\author{
Fernando PÉREZ CABELLO y Juan DE LA RIVA FERNÁNDEZ \\ Departamento de Geografía y Ordenación del Territorio \\ Universidad de Zaragoza
}

\begin{abstract}
Resumen: En este trabajo se presenta una metodología para la detección de superficies afectadas por fuegos forestales mediante el empleo de imágenes Landsat TM. El ensayo se ha realizado en el Prepirineo occidental oscense, área especialmente afectada por los incendios forestales. La utilización de este tipo de información puede colaborar en las tareas de detección de daños causadas por estas perturbaciones apoyando activamente los métodos tradicionales.
\end{abstract}

Palabras clave: Incendio forestal, Teledetección, Landsat TM, Índice de Vegetación Normalizado (NDVI).

\begin{abstract}
A methodology for deteccion of surfaces affected by forest fires by using Landsat TM images is shown in this paper. The site of the study is based in the western Pyrennes of Huesca (Aragón) where often ocurr. The use of this kind of information can help in detecting damages caused by these events suporting traditional methods.
\end{abstract}

Key words: Forest fire, Remote Sensing, Landsat TM, Normalized Difference Vegetation Index (NDVI).

\section{INTRODUCCIÓN}

Los incendios forestales constituyen una amenaza real para la conservación de nuestros bosques. Aunque en la cuenca mediterránea el fuego se ha presentado a lo largo de la historia como un elemento natural, su recurrencia y magnitud está degradando, y en ocasiones aniquilando, las estructuras de los sistemas forestales afectados. Sólo en la provincia de Huesca, entre 1985 y 1994 ardieron 20580 has en un total de 845 incendios, lo que da buena cuenta de la magnitud del problema. 


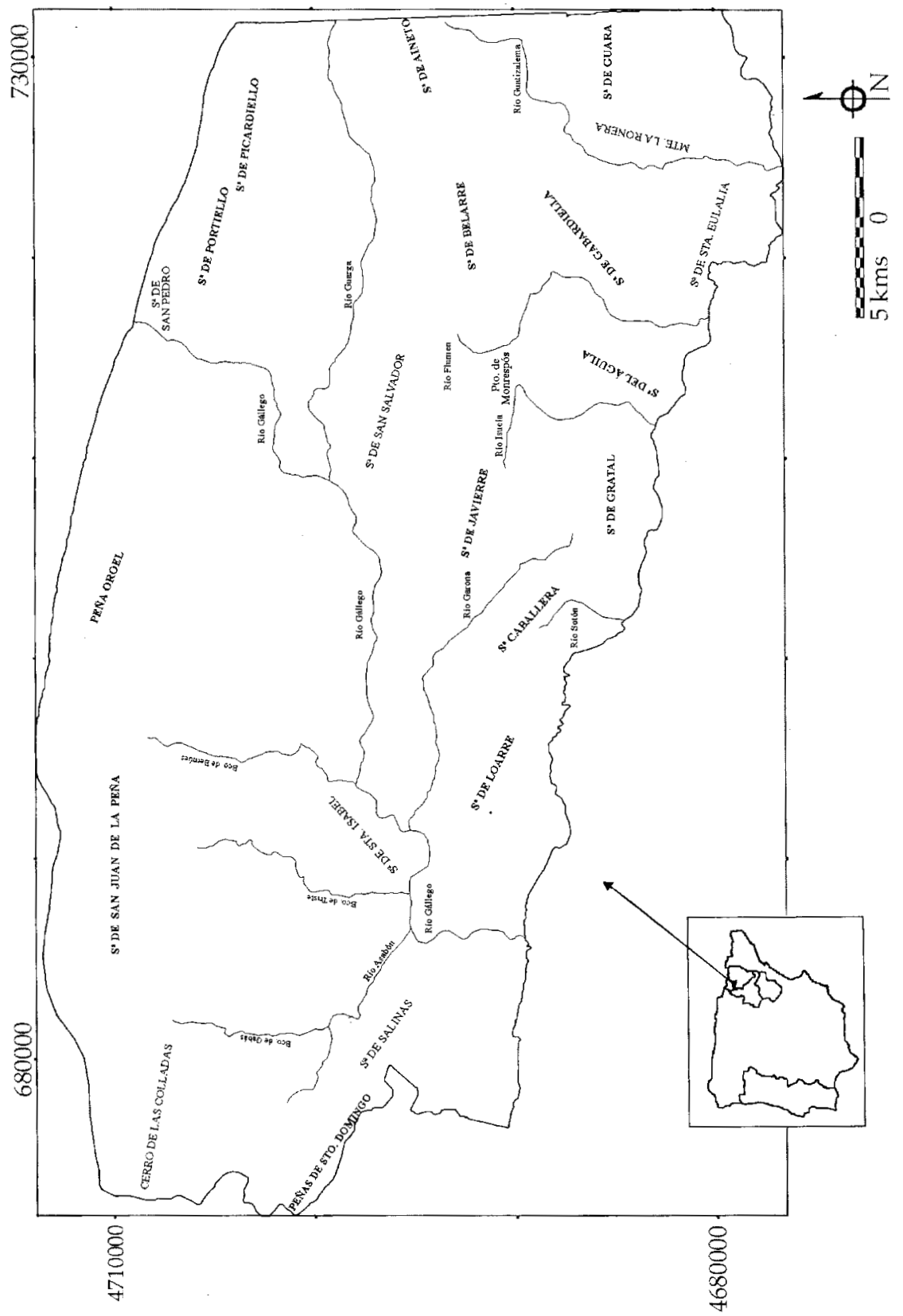

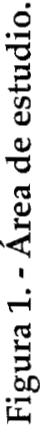


Desde el punto de vista del control y evolución de este tipo de perturbaciones, el empleo de técnicas de teledetección y concretamente el uso de imágenes Landsat-5 (sensor Thematic Mapper, TM) ofrece posibilidades muy interesantes, por cuanto permite la detección y evaluación de los espacios afectados, favoreciendo sustancialmente las tareas de estimación de daños y su seguimiento a lo largo del tiempo.

Las aplicaciones de la teledetección al análisis de los incendios forestales se pueden agrupar en tres ámbitos: momento previo, simultáneo y posterior al fuego; los dos primeros integran, respectivamente, estudios dirigidos a la determinación de índices de peligrosidad y la detección de focos activos, mientras que el tercero reúne estudios sobre la evaluación y consecuencias de los fuegos.

Es precisamente en este último ámbito donde se inscribe el presente trabajo, sobre la base de la delimitación y cartografía de los espacios afectados por incendios forestales entre 1985 y 1994 en el Prepirineo occidental oscense, zona especialmente afectada por este tipo de alteraciones ambientales.

\section{ÁREA DE ESTUDIO}

La zona de estudio es un territorio típico de media montaña de $1481 \mathrm{~km}^{2}$ inscrito en el complejo montañoso que constituyen las estribaciones meridionales del Pirineo occidental aragonés (Figura 1). Este área forma parte de la unidad del Prepirineo, extendiéndose por dos de sus tres subunidades principales: Sierras Exteriores (Loarre, Caballera, Gratal, Aguila, Gabardiella y Guara) y Depresión Media.

La Figura 2 muestra una composición de color de la imagen Landsat TM del 24 de agosto de 1989 del territorio considerado. Tras un rápido vistazo podemos destacar las zonas con vegetación (tonos verdes), cubriendo casi en su totalidad los relieves serranos inscritos en el área de estudio, y las zonas cultivadas y desprovistas de vegetación (grises) que, aunque menos abundantes que las anteriores, ocupan una amplia extensión, concentrándose especialmente en el tramo medio del Gállego -parte central de la imagen-, el valle de río Matriz y las depresiones de Abena, Bailo y Agüero, estas dos últimas en el extremo occidental.

Climáticamente destaca su carácter transicional como consecuencia de una singular situación geográfica entre ambientes mediterráneos continentalizados por el sur y atlánticos de montaña por el norte, dentro de un contexto general de carácter submediterráneo. 


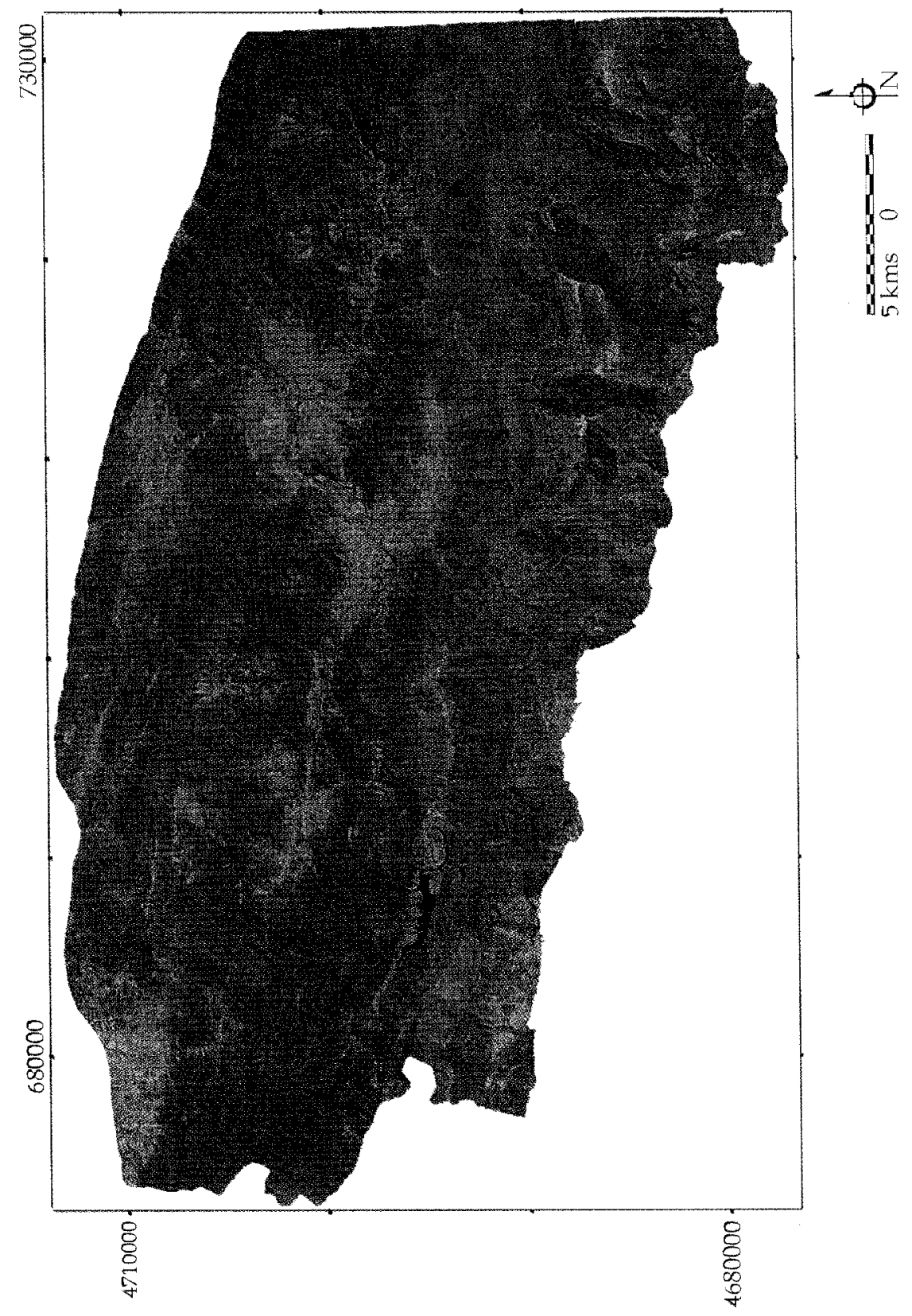

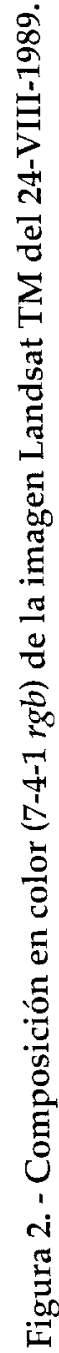


Biogeográficamente presenta una compleja situación al constituir un espacio bisagra entre la Región Eurosiberiana y la Mediterránea, lo que sumado a la actuación del hombre explica la naturaleza y distribución de una vegetación constituida principalmente por vastas repoblaciones de coníferas, quejigales y encinares con distinto grado de madurez y formaciones subarbustivas y arbustivas.

El alto grado de combustibilidad de esta vegetación, la profusión de tormentas secas en verano y el abandono de las actividades socio-económicas tradicionales explican en buena parte las causas de los numerosos incendios que se registran en este ámbito pirenaico.

\section{METODOLOGÍA}

El proceso metodológico desarrollado se articula en las siguientes fases:

- Selección de las imágenes digitales.

- Corrección geométrica y atmosférica de las mismas.

- Detección de las áreas incendiadas.

- Cartografía de los incendios forestales.

\section{Selección de las imágenes digitales}

Las imágenes seleccionadas proceden del satélite Landsat-5 sensor TM, que proporciona imágenes de 8 bits en siete bandas espectrales: tres visibles ( 1 a 3 ), una en el infrarrojo próximo (4), dos en el medio (5 y 7) y una en el térmico (6); con una resolución espacial de $30 \mathrm{~m}$ en las reflectivas, estas imágenes son especialmente adecuadas para la cartografía temática y el análisis multitemporal.

Para este trabajo se ha contado con cinco imágenes cedidas por el Servicio de Investigaciones Agrarias y el Instituto Pirenaico de Ecología; las fechas de las mismas son las siguientes: 24 de agosto de 1989, 12 julio de 1990, 24 de agosto de 1991, 12 de julio de 1993 y 29 de junio de 1994. El hecho de que la mayor parte de las disponibles sean de verano evita la existencia de conflictivas superficies enmascaradas por sombras topográficas, típicas de las imágenes de finales del otoño e invierno en áreas de montaña, si bien aumenta la posibilidad de confusión con campos de cultivo y zonas de vegetación natural secas, ya que éstas tienen una respuesta espectral similar a la de la vegetación quemada.

\section{Corrección de las imágenes empleadas}

Las imágenes de satélite presentan alteraciones tanto en la localización como en el valor de las señales detectadas que reciben, respectivamente, el nombre de 
distorsiones geométricas y radiométricas. Estas alteraciones se deben principalmente a los efectos de la rotación terrestre, al mal funcionamiento de alguno de los instrumentos que intervienen en el sistema de teledetección (plataforma espacial, sensor, antena receptora) y al papel desempeñado por la atmósfera. Por tanto, en esta segunda fase del trabajo se han corregido las imágenes, en el sentido de disponerlas lo más adecuadamente posible para su interpretación y tratamiento, mediante la aplicación de dos procesos de corrección: geométrico y atmosférico.

\section{Corrección geométrica.}

La corrección aplicada ha consistido en un proceso de transferencia de las muestras radiométricas de la imagen a una nueva malla georreferenciada mediante un método de asignación. Las tres fases principales que ha implicado este proceso de corrección son las siguientes:

- Obtención de puntos de control.

- Establecimiento de los coeficientes de transformación.

- Reubicación de los píxeles de la imagen.

La primera fase, básica para realizar con exactitud el proceso de corrección, consistió en la localización, en ambos soportes (imagen y mapa), de 458 puntos comunes. En nuestro caso se utilizó la imagen de 1990 que una vez corregida sirvió de referencia para corregir el resto de las imágenes mediante el programa de tratamiento digital Dimple (1990) que permite la visualización simultánea de dos imágenes facilitando la búsqueda de puntos comunes.

A continuación se eligió un modelo de deformación -polinómica de primer ordenpara calcular los coeficientes de transformación. El nivel de ajuste y la desviación que se produce al aplicar el polinomio se computó mediante el error cuadrático medio (RMS) que en ninguno de los casos fue superior a un píxel.

Finalmente se procedió a la transferencia de los niveles digitales (ND) originales a la nueva malla georreferenciada mediante el método de asignación del vecino más próximo. Este método no distorsiona la señal radiométrica ya que asocia a cada píxel de la imagen resultante el ND del más próximo en la inicial.

\section{Corrección atmosférica.}

Para corregir, al menos en parte, las distorsiones producidas por la atmósfera en la señal recibida por el sensor se aplicó a las imágenes un sencillo proceso de corrección consistente en la sustracción a todos los niveles digitales de cada una de ellas del valor mínimo hallado en cada banda. Se presupone que la reflectividad de las zonas 
con sombra topográfica debe ser cero; por tanto, la diferencia entre este valor y el mínimo registrado constituye el efecto de la dispersión atmosférica. Este método, aunque resulta incompleto y puede ocasionar sobrecorrecciones en algunas bandas, es suficiente en relación con el objetivo del presente trabajo.

\section{Detección y cartografía de los incendios forestales}

En líneas generales, la respuesta espectral de la vegetación en buen estado se caracteriza por presentar valores de reflectividad muy bajos en el dominio del visible, debido a la fuerte absorción de energía de ciertos pigmentos, y valores notablemente más altos en la región del infrarrojo próximo, variables en relación con la estructura interna de las hojas; en el infrarrojo medio la reflectividad de la vegetación vuelve a experimentar un descenso considerable debido a que el agua contenida en la hoja absorbe grandes cantidades de energía (Figura 3).

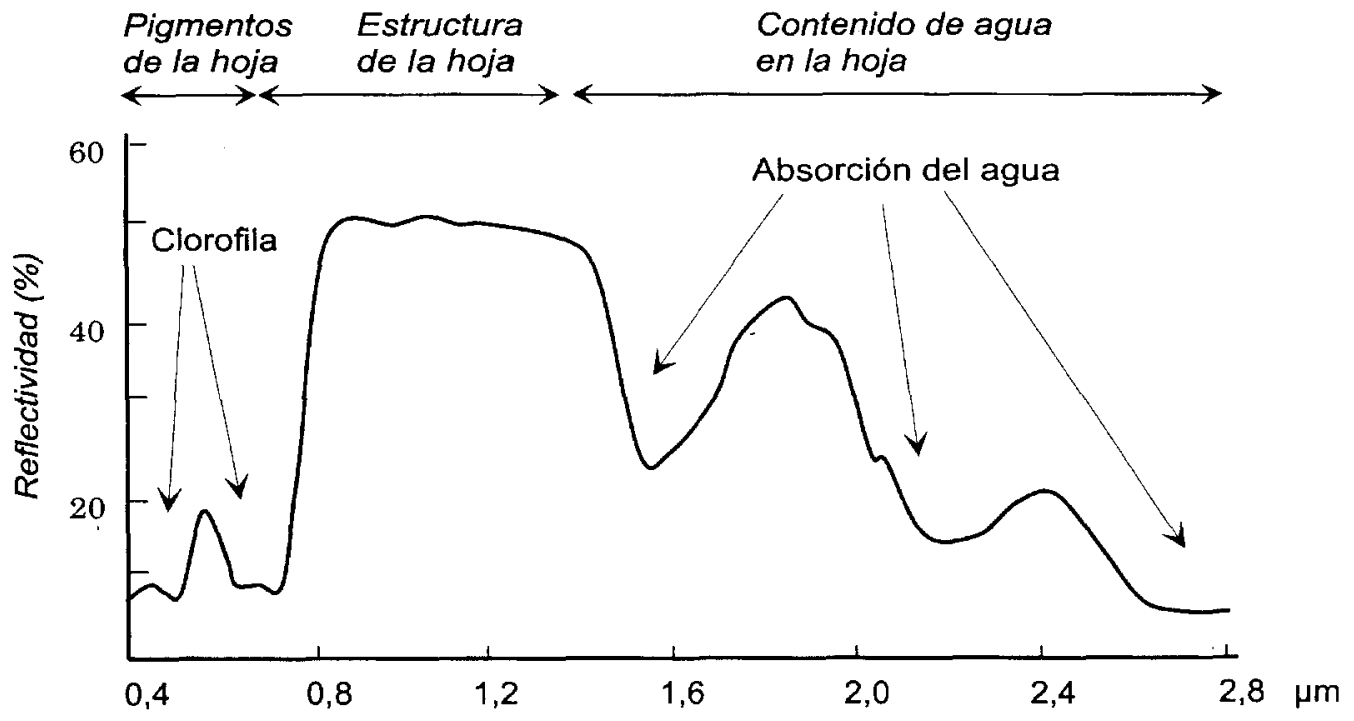

Figura 3. - Factores de la reflectividad de la vegetación sana en el espectro óptico (Chuvieco, 1996). 


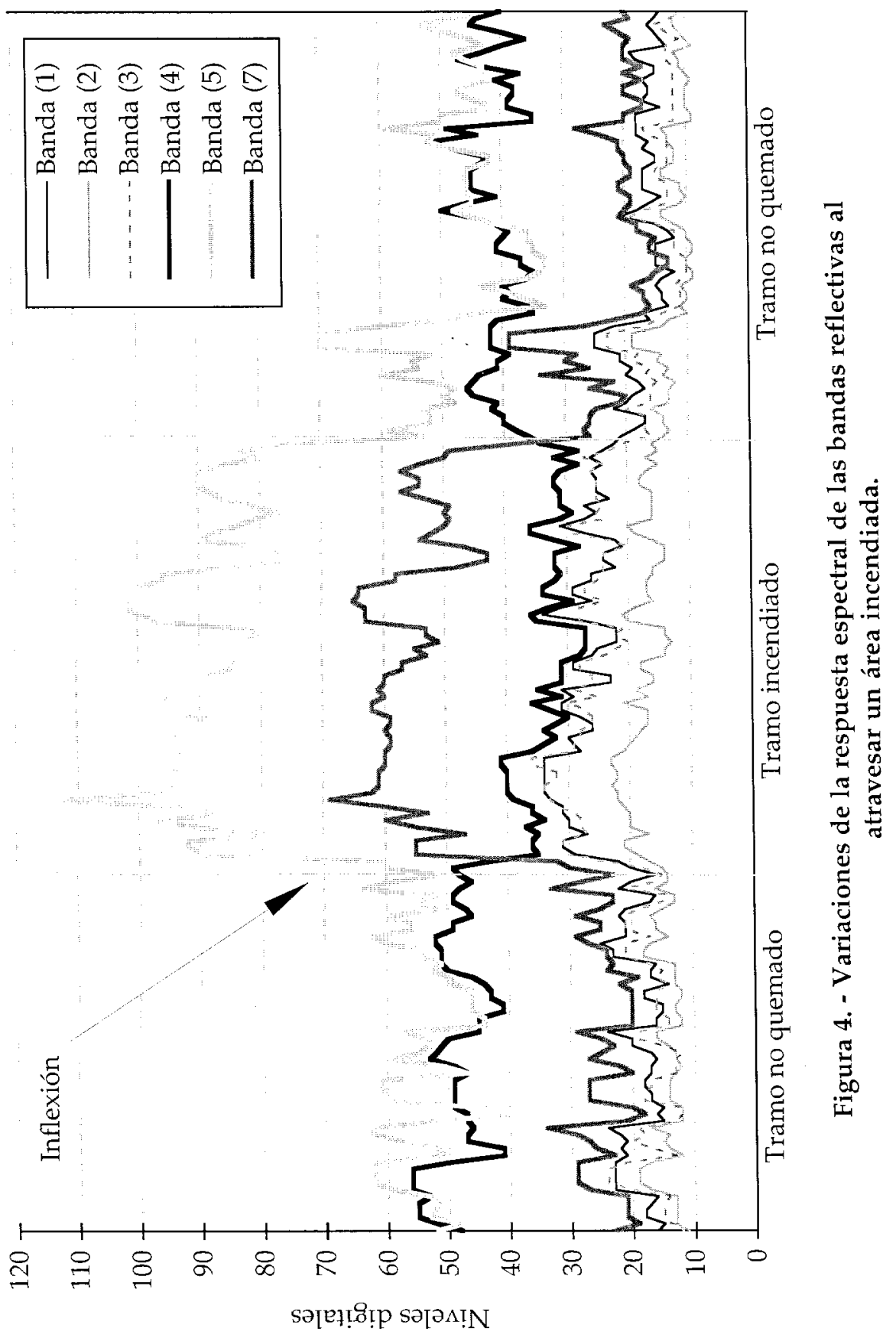


De este modo, aunque los valores de reflectividad varían según la especie, las disponibilidad hídricas de la planta y el momento del año, el comportamiento espectral de la vegetación sana suele presentar una curva, en condiciones de laboratorio, del mismo tenor que la que se reproduce en la Figura 3. Ahora bien, cuando la vegetación se somete a cualquier tipo de tensión, estrés hídrico, un incendio, etc., su comportamiento espectral varía de manera muy notable.

En el caso del fuego, el efecto radiométrico más reseñable consiste en un aumento de la respuesta en todas las bandas del espectro electromagnético, excepto en la 4, donde disminuye debido a la destrucción de la estructura interna de la hoja. Los aumentos más espectaculares se producen en las bandas 7 y 5 , especialmente en esta última debido a la desaparición del agua contenida en la estructura interna de las hojas. En el transecto espacial representado en la Figura 4 se puede advertir las variaciones de intensidad que experimentan los niveles digitales en cada banda espectral a su paso por tres tramos diferentes: dos de ellos no quemados y uno central afectado por un incendio.

En primer lugar, se puede observar con claridad la fuerte inflexión ascendente que experimentan todas las bandas del visible y del infrarrojo medio, en especial estas últimas, al acceder al tramo incendiado, y cómo vuelven a su nivel anterior al salir del área quemada. En cambio, la banda 4, perteneciente al infrarrojo cercano, registra un ligero descenso al entrar en el tramo quemado, volviendo a su situación de partida al abandonarlo.

Estas variaciones radiométricas de los niveles digitales en las diferentes bandas posibilitan la identificación de los incendios forestales mediante dos formas principales: análisis visual y tratamiento digital.

El análisis visual se realiza especialmente a partir de combinaciones de color y ciertos realces, mientras que los tratamientos digitales presentan un amplia gama de posibilidades: clasificaciones supervisadas o no supervisadas, particiones del histograma bidimensional, máscaras radiométricas a partir de uno o varios canales, máscaras gráficas, ratios o canales brutos, bandas artificiales, etc. (CHUVIECO, 1996).

Entre los ratios más utilizados se encuentran los índices de vegetación, que se fundamentan en el singular comportamiento espectral que presenta la vegetación. De entre éstos destaca de modo especial, por su profusa utilización y fácil cálculo, el Índice de Vegetación Normalizado (NDVI) que, según indica HAYES (1985), está muy correlacionado con el índice de superficie foliar, la biomasa y la productividad neta. La formulación del NDVI para las imágenes Landsat TM es la siguiente:

$$
N D V I=((\text { banda } 4-\text { banda } 3) /(\text { banda } 4+\text { banda } 3))
$$




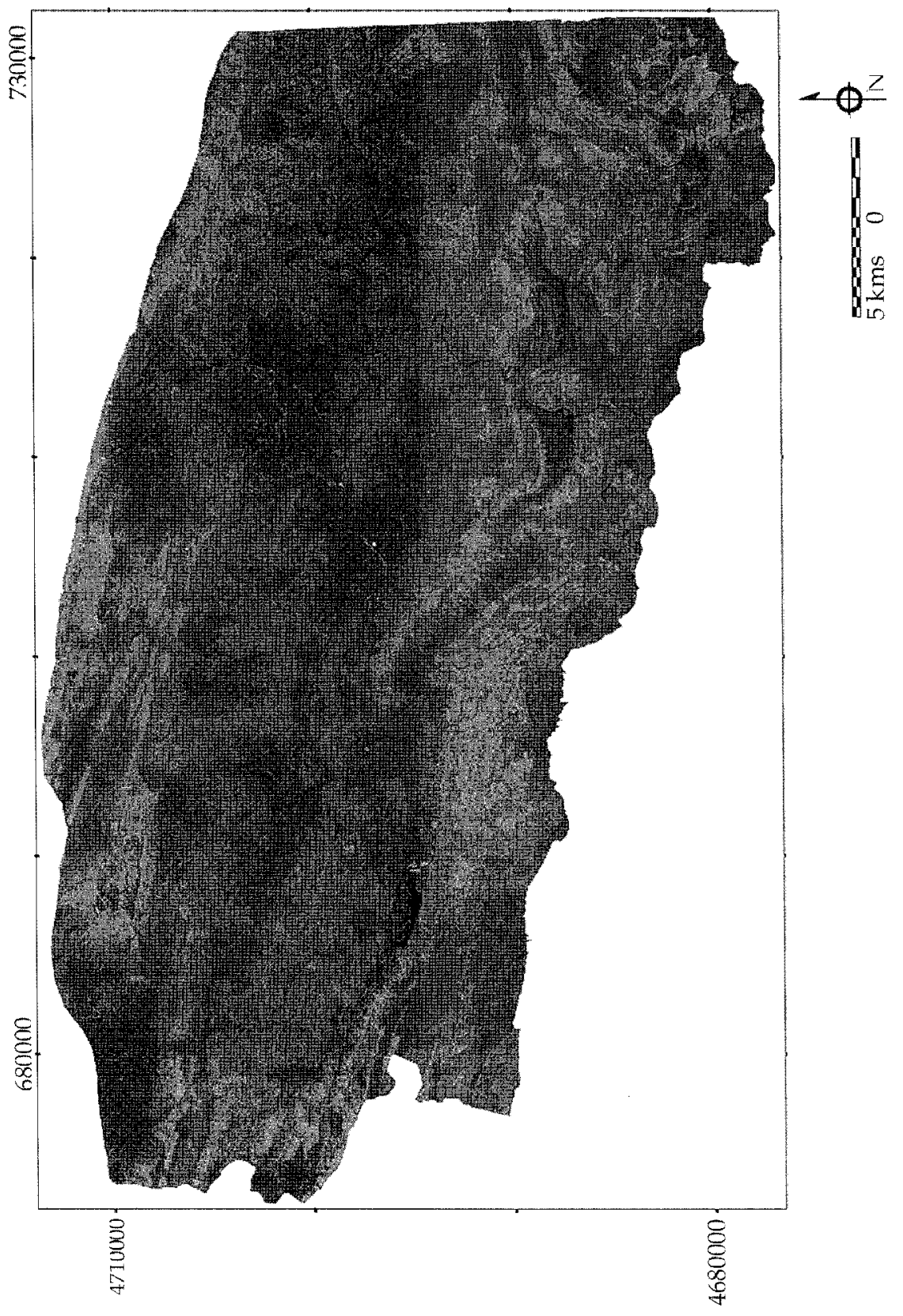

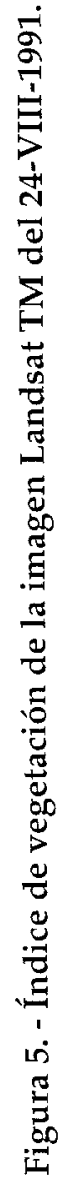


La Figura 5 muestra un ejemplo de la aplicación de este índice a la imagen del 24 de agosto de 1991. Las zonas con mayor vigor vegetal aparecen representadas con tonos claros mientras que los grises más oscuros se corresponden con las zonas con menos vegetación, áreas urbanas, embalses, carreteras, espacios incendiados recientemente, etc.

En lo que respecta al análisis visual, el proceso consiste en asignar un color determinado, dentro de los tres posibles (rojo, verde y azul), a los niveles digitales de una banda concreta, de tal modo que cuanto más alto sea el nivel digital mayor será la intensidad del color que se le aplique.

Una de las combinaciones de color que mejores resultados ofrece es la 7-4-3 en donde el rojo $(r)$ se ha aplicado a la banda 7 -infrarrojo medio-, el verde $(g)$ a la banda 4 -infrarrojo próximo- y azul (b) a la banda 3 -segmento rojo del espectro visible-. La Figura 6 recoge los resultados de esta combinación en una zona antes de ser afectada por un incendio (parte superior) y después del mismo (parte inferior). El aspecto más reseñable lo constituye la transformación de los tonos verdes, característicos de 1 a vegetación en esta combinación, en los rojos y magentas de la imagen que recoge la zona tras haberse producido el fuego, debido al aumento de la reflectividad en la banda 7 y al descenso en las bandas 3 y 4.

En nuestro caso se ha hecho uso conjunto de técnicas de análisis visual a partir de composiciones de falso color, especialmente (7-4-3 rgb), y la generación de los NDVI de las imágenes disponibles. Además se ha contado con el apoyo de los partes de incendio, informes que recogen importante información en relación con la ubicación y materiales afectados. No obstante, es preciso señalar que el proceso de detección no h a estado exento de problemas. En primer lugar, la identificación de los incendios ocurridos antes de 1987 se ha visto dificultada por la ausencia de imágenes para los años 1985 y 1986, ya que las técnicas descritas no ofrecen la misma eficacia que al poco tiempo de ocurrir el incendio. En segundo lugar, ha habido una cierta confusión a la hora de discriminar algunos incendios de campos de cultivo y zonas de vegetación natural seca, ya que éstas presentan una respuesta espectral semejante a las zonas quemadas. Asimismo, hay que señalar que se han cartografiado los incendios más importantes desde el punto de vista del tamaño (mayores de $40 \mathrm{ha}$ ), ya que con una resolución de $30 \mathrm{~m}$ no todos son detectables, sino tan sólo aquellos que presentan una cierta magnitud espacial y determinadas características espectrales.

Finalmente, mediante el módulo de digitalización de Ilwis 1.3 (ITC, 1992) se han digitalizado los diferentes perímetros generando una cartografía mediante las funciones típicas de este SIG raster (Figura 7). 

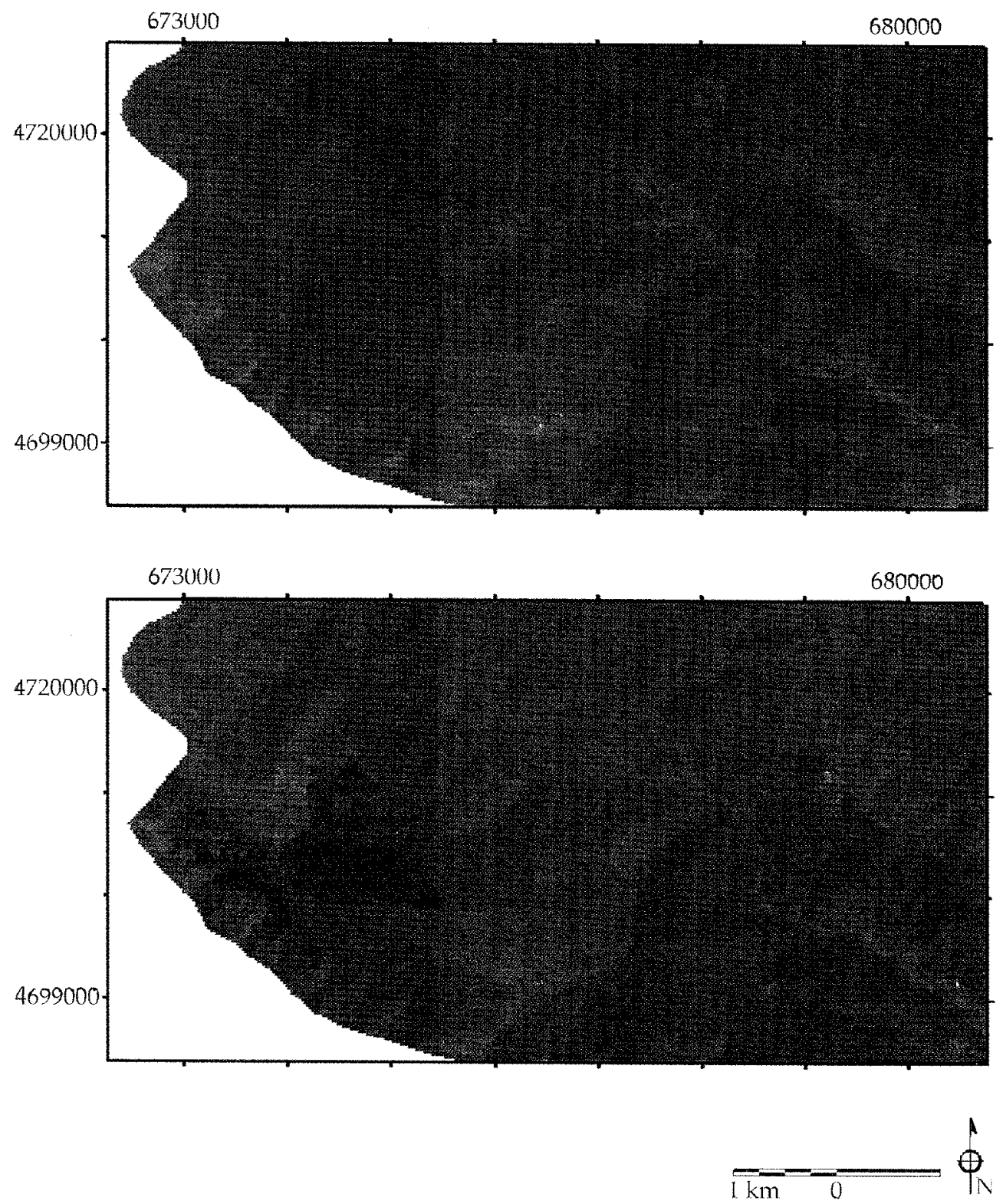

Figura 6. - Composición en falso color (7-4-3 rgb) del incendio de la pardina Nofuentes; antes del fuego -parte superior, 1989- y después del fuego-parte inferior, 1990-. 


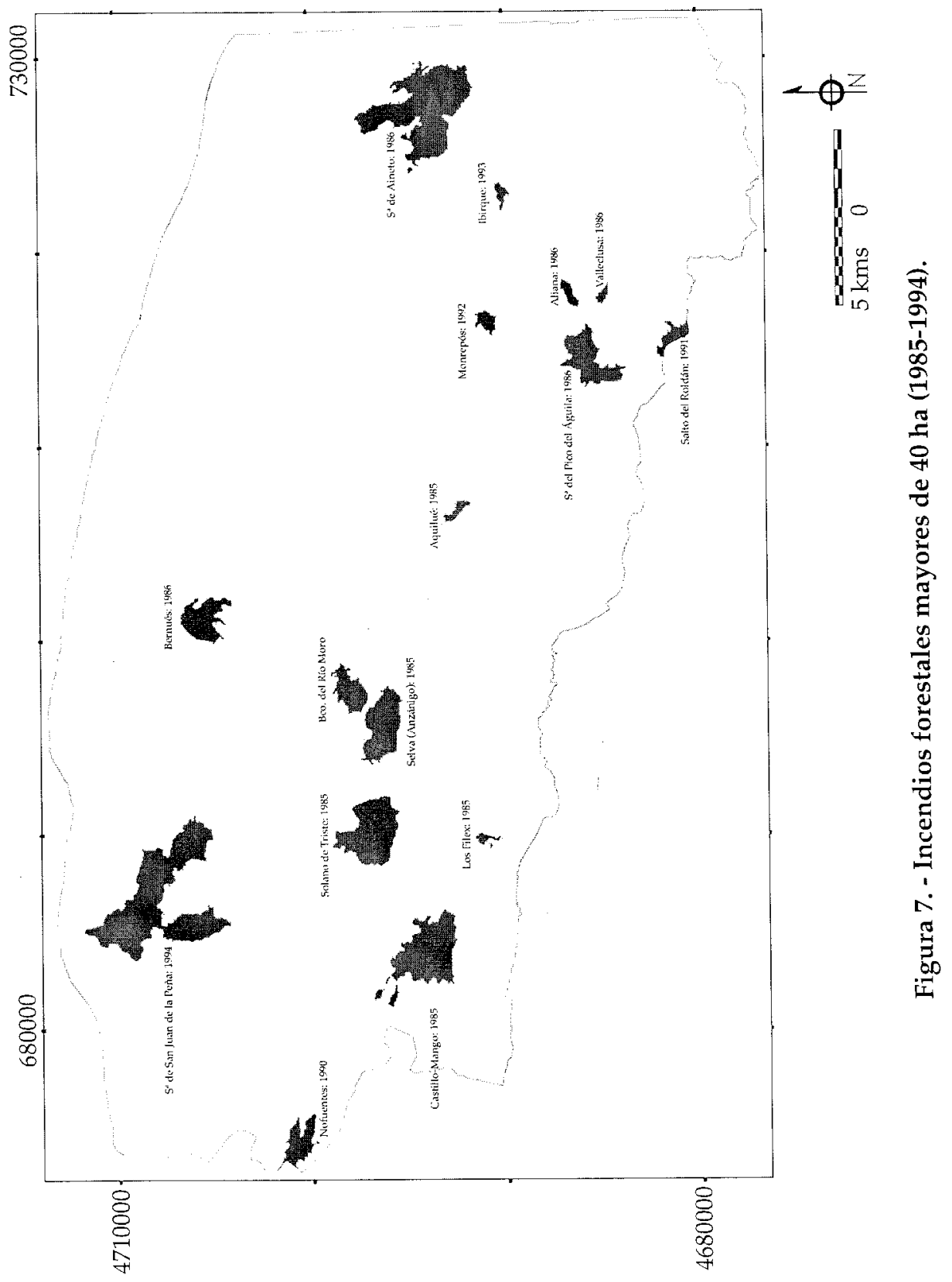




\section{CONCLUSIONES}

Las imágenes de satélite Landsat-5 (TM) y su integración en un SIG posibilitan la elaboración de la cartografía de los diferentes espacios afectados por fuegos forestales en el área estudiada.

La corrección aplicada a las diferentes imágenes se manifiesta como un proceso imprescindible a la hora de elaborar este tipo de cartografía. La utilización conjunta de combinaciones en falso color (7-4-3 rgb) y el uso del NDVI ha ofrecido excelentes resultados a la hora de detectar los diferentes espacios afectados.

El hecho de que las imágenes utilizadas sean de verano, aunque en principio aumenta la posibilidad de confusión con campos de cultivo y zonas de vegetación natural seca, evita la aparición de superficies enmascaradas por las sombras topográficas típicas de las imágenes de finales del otoño e invierno en áreas de montaña.

Finalmente, señalar que la elaboración de cartografías como la presentada en este trabajo puede apoyar sustancialmente la definición de programas de actuación para la evaluación de espacios afectados por este tipo de perturbaciones, constituyendo una herramienta útil para complementar los métodos de estimación tradicionales, al tiempo que permite el seguimiento a lo largo del tiempo de estas superficies desde el punto de vista de la erosión y los procesos de revegetación (PÉREZ, 1996).

\section{Agradecimientos}

Este trabajo se inscribe en uno de mayor envergadura titulado: "Estudio de procesos ambientales en zonas afectadas por fuegos forestales mediante datos de campo y técnicas de teledetección en el Prepirineo occidental oscense", subvencionado por la Diputación General de Aragón. Además ha sido posible gracias al apoyo financiero del Instituto de Estudios Altoaragoneses y de la Universidad de Zaragoza.

\section{BIBLIOGRAFÍA}

ARBIOL, R., ROMEU, J. y VIÑAS, O. (1986): “Detección de los incendios forestales en Catalunya a partir de imágenes digitales del sensor TM de satélite Landsat- 5 ", en Comunicaciones de la $I^{a}$ Reunión Cientifica del Grupo de Trabajo en Teledetección, pp. 199-215, Barcelona.

CHUVIECO, E. (1996): Fundamentos de teledetección espacial, Ediciones Rialp, 568 pp., Madrid. 
DE LA RIVA, J. (1997): Los montes de la Jacetania. Caracterización física y explotación forestal. Publicaciones del Consejo de Protección de la Naturaleza de Aragón n 10, 357 pp., Zaragoza.

DIMPLE (1990): Dimple. Digital Image Processing System. User Manual, Proccess Software Solutions Pty. Ltd., Wollongong (Australia).

ERDAS (1991): Field Guide, Erdas v. 7.5., Erdas Inc., Atlanta.

HAYES, L. (1985): “The current use of TIROS-N series of meteorological satellites for land-cover studies", International Journal of Remote Sensing 6(1), pp. 35-45.

HUETE, A.R. (1987): "Spectral signatures and vegetation indices", en II Reunión Nacional del Grupo de Trabajo en Teledetección, pp. 13-26, Valencia.

I.T.C. (1992): Ilwis 1.3 User's Manual, International Institute for Aerospace Survey and Earth Sciences, The Netherlands.

NAVARRO, C. (1991): "Uso de las imágenes Landsat-TM en un sistema de evaluación de daños causados por incendios forestales", en Teledetección y Medio Ambiente (Actas de la IV Retinión científica de la Asociación Española de Teledetección), pp. 51-59, Sevilla.

PÉREZ, F. (1996): "Metodología para el análisis de la dinámica ambiental en zonas incendiadas del Prepirineo occidental oscense", APT-Berichte 7, pp. 175-184, Universidad de Friburgo.

VIEDMA, O. y CHUVIECO, E. (1994): "Cartografía y evaluación de daños causados por incendios forestales mediante técnicas de teledetección. El ejemplo de la Hoya de Buñón (Valencia)", AITIM Boletín de información técnica 167, pp. 60-66. 